\title{
EDITORIAL
}

\section{LA CRISIS FINANCIERA Y LA SALUD}

A nivel mundial y también local, los últimos meses han estado marcados por la crisis financiera, cuyo origen se describe y analiza con detalle en todos los medios pero cuyo alcance, severidad y duración nadie puede precisar con plena certeza. Podemos evidenciar los efectos de la crisis en muchos ámbitos, muy especialmente en el sector financiero y en la economía de las personas. La frase de Josh Billing (EE.UU., 1818-1885) "El dinero es como la salud, nunca lo valoramos bien hasta que los perdemos", cobra valor en la vida real de muchas personas.

La industria de la salud es una de las más importantes y de mayor crecimiento en el mundo, constituyendo una fracción relevante de los mercados financieros, dentro de la que destacan las empresas farmacéuticas y los proveedores de equipos y servicios. Este sector ha mostrado utilidades estables, siendo considerado por los economistas como muy expuesto a riesgos regulatorios y políticos. A nivel nacional, si bien se ha mencionado que nuestro país estaría de alguna manera "protegido", "blindado" o "en un buen pié", hemos sido testigos de gran cantidad de noticias financieras negativas, especulaciones varias y además se han sentido los efectos de medidas preventivas/ paliativas adoptadas para enfrentar la situación, todo lo cual nos ha producido un cierto desaliento e incertidumbre.

Pero no todo es tan negativo; en una charla reciente, Axel Christensen, destacado economista, analizó las perspectivas para el sector salud, evaluándolas a corto y mediano plazo como "neutro a negativo" y a largo plazo como "positivo", con fundamentos que sería largo enumerar. Respecto de la salud de las personas, destaca que si bien la intuición podría llevar a pensar sólo en impactos negativos como aumento de infartos, suicidios, depresiones y otros, la evidencia indica que también hay efectos positivos como por ejemplo: se ha demostrado que la disminución del valor del tiempo ayuda a aumentar el cuidado parental de los niños y, por otra parte, en tiempos de bonanza económica aumenta el stress laboral y disminuye el tiempo disponible para la prevención.

Para sobreponernos al desaliento y la incertidumbre, vale la pena recordar a Khalil Gibran (1883-1931), ensayista, novelista y poeta libanés: "Por muy larga que sea la tormenta, el sol siempre vuelve a brillar entre las nubes". 